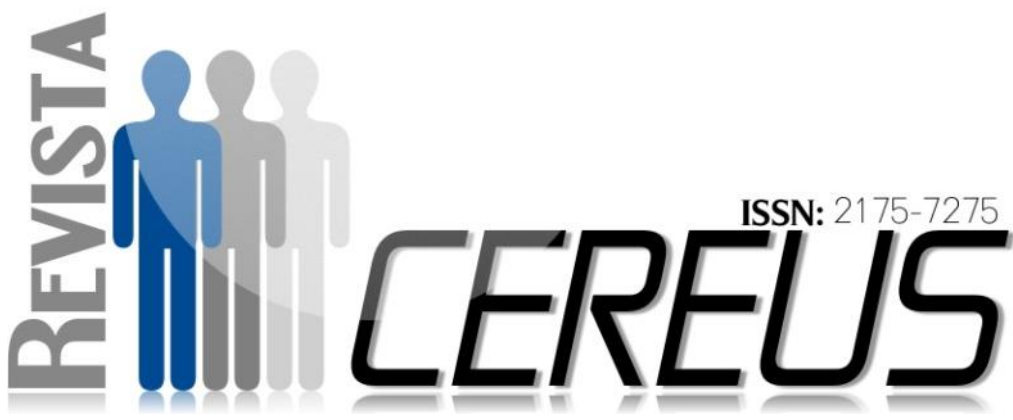

DOI: 10.18605/2175-7275/cereus.v9nep19-33.

\section{CONTRATOS ELETRÔNICOS À LUZ DO CÓDIGO DE DEFESA DO CONSUMIDOR}

SANTOS, Michelly Geraldo dos ${ }^{1}$

RESUMO

FURLAN,Fernando Palma Pimenta ${ }^{2}$;

Atualmente percebemos que diversas são as relações de consumo que praticamos no nosso dia a dia. Desde que existimos que somos considerados consumidores em potencial. Pratica esta advinda desde séculos passados perdurando até os dias de hoje, seja com o comércio antigo com a troca como moeda, ou com o mercado atual e cotidiano com moeda corrente. Contudo, diversos são os meios para realizar o consumo de um bem ou serviço: indo diretamente no local e firmando contrato diretamente com a parte contratante ou por meio do contrato eletrônico, ou seja, o celebrado por meio da internet. Este artigo tem por objetivo analisar as nuances do contrato eletrônico e a aplicação do Código de Defesa do Consumidor. Entende-se por contrato eletrônico a transação onde duas ou mais pessoas utiliza-se

\footnotetext{
${ }^{1}$ Acadêmica do curso de direito do Centro Universitário UNIRG, Gurupi - TO.

2 Docentes do Curso de direito do Centro Universitário UnirG, Gurupi-TO. E-mail: furlanadvocacia@hotmail.com
} 
da internet com o forma de manifestação da vontade e assim firmarem um contrato. Em virtude da sua recorrente busca por parte da sociedade para compras, haja vista sua praticidade e comodidade, necessária se fez também que a legislação brasileira acompanhasse esse avanço. Observa-se que os princípios aplicados aos contratos eletrônicos são os mesmos exigidos nos contratos convencionais. Embora o assunto seja carente de doutrina ou jurisprudências, justifica a relevância do assunto tendo em vista o crescente número destas transações realizadas por meio do comércio eletrônico. Por isto, este artigo pretende formular uma interpretação dos contratos eletrônicos praticados no e-commerce, haja vista a atualidade do tema, à luz da nova hermenêutica contratual, que se baseia no direito civil-constitucional e no Direito do Consumidor.

Palavras chave: contratos, comércio eletrônico, código de defesa do consumidor.

\section{ELECTRONIC CONTRACTS IN THE LIGHT OF THE CONSUMER PROTECTION CODE.}

\section{ABSTRACT}

Currently we realize that many are consumer relations that we practice in our daily lives. Since that exist are considered potential consumers. This practice arising from past centuries lasting until today, either with the old trade with the exchange as currency, or the current market and with everyday currency. However, many are the means to the consumption of a good or service: going directly on site and entering into contract directly with the contracting party or through the electronic contract, ie, the celebrated through the Internet. This article aims to analyze the nuances of the electronic contract and the application of the Consumer Protection Code. It is understood by electronic contract transaction where two or more persons 
is used the internet as a form of manifestation of will and thus enter into a contract. Because of its recurring search by the company for purchases, given its practicality and convenience needed it was made also that Brazilian law accompany this advance. It is observed that the principles applied to electronic contracts are the same as required in conventional contracts. Although it is lacking in doctrine or jurisprudence, justifies the relevance of the subject in view of the increasing number of these transactions through e-commerce. Therefore, this article aims to formulate an interpretation of electronic contracts used in e-commerce, given the topicality in the light of new contractual hermeneutics, which is based on civil and constitutional law and consumer law.

Keywords: contracts, e-commerce, consumer protection code 


\section{INTRODUÇÃO}

O presente artigo tem o intuito de apreciar a aplicação do Código de Defesa do Consumidor - CDC - aos contratos firmados por meio eletrônico. Esta relação de comércio é bastante utilizada pela sociedade atualmente, impondo, desta forma, que este tipo de comércio tenha regulação pelo Direito.

Neste sentido, este trabalho irá apresentar alguns pontos relevantes acerca dos contratos eletrônicos enquanto negócios jurídicos firmados por meio de declaração de vontade autônomas, que são regulados, via de regra, pelos mesmos dispositivos que tratam das demais espécies de contratos.

Ressalte-se que "o princípio da não discriminação é o que se aplica aos contratos eletrônicos, significando que podem invocar tão somente a presença do meio digital para descartá-la" (LORENZETTI, p. 553, 2008). Contudo, evidencia-se também a dificuldade que há em delimitar exatamente qual o regime jurídico que deverá reger os casos que envolvem esta modalidade de contratos.

Outro ponto relevante e que vale lembrar é o que diz respeito à identificação dos valores e interesses envolvidos na contratação eletrônica quando busca aplicar-se cláusulas gerais que o Código Civil estabelece. Um exemplo claro é a função social dos contratos e a boa-fé objetiva empregada, que caracterizam-se como elementos essenciais para a integração hermenêutica de qualquer que seja o negócio jurídico.

O tema trabalhado está recebendo atualmente a devida atenção. No entanto, informa-se a escassez de estudos e debates jurídicos acerca do mesmo, o que espera que seja ampliado devido a sua atualidade. Desta forma, procura-se neste trabalho abordar a defesa do consumidor face aos contratos eletrônicos e a aplicação do Código de Defesa do Consumidor.

Quando se trata de contratos eletrônicos, essencial destacar os princípios da boa-fé objetiva e o direito de arrependimento, constituindo estes de base para os operadores do Direito. 


\section{MATERIAIS E MÉTODOS}

Foi realizada uma pesquisa utilizando às terminologias cadastradas bibliográfica através de revisão de nos Descritores em Direito do literatura por meio da utilização de livros e artigos científicos disponíveis nas bases de dados Scielo, Capes Periódicos, jurisprudências e doutrinas brasileiras. A pesquisa destes materiais bibliográficos foram realizados entre fevereiro e maio de 2016. A busca nos bancos de dados foram realizadas Consumidor, com as palavras-chaves contratos eletrônicos e código de defesa do consumidor. Para análise utilizamos algumas variáveis como: ano de publicação, profissão dos autores, local da pesquisa, instrumento utilizado, amostra e revista de publicação.

\section{ANTECEDENTES HISTÓRICOS DO CÓDIGO DE DEFESA DO CONSUMIDOR}

Como se viu, a inclusão da mediação e da conciliação no âmbito do judiciário brasileiro representa um grande avanço na busca pela resolução consensual dos conflitos levados a apreciação do magistrado.

O que se pode observar é que o legislador possuía a melhor das intenções ao dar tamanha ênfase ao instituto da mediação e sua obrigatoriedade dentro do sistema processual. Acontece que nem tudo é tão simples quanto parece.

Ao mesmo tempo em que todos estão confiantes de que a mediação representa uma solução mais benéfica do que o desgaste da relação entre as partes após a submissão do conflito à apreciação do juiz, é crescente a preocupação no que se refere à adaptação dos profissionais do direito e dos fóruns brasileiros.

Tudo isso porque o NCPC, ao disciplinar a conciliação e mediação judicial, determinou que os fóruns das comarcas de todo o Brasil tem a obrigação de instituir os centros judiciários de solução consensual de conflitos - CEJUSC, local onde se realizarão as audiências de mediação e conciliação. Aqui reside uma das preocupações.

Parte dos estudiosos alertam que 0 poder público não possui condições para viabilizar a criação de tais centros em todas as comarcas 
existentes, e, provavelmente, os fóruns irão se adaptar na medida de suas condições, de modo que seria impossível afirmar que quando do início da vigência da nova lei os centros de mediação, na forma prevista no NCPC, sejam uma realidade acessível de todos.

Somada à dificuldade de reestruturação, a preocupação maior reside na insuficiência de mediadores profissionalmente capacitados para exercer um cargo de tamanha relevância, já que é notório e evidente o fato de que as comarcas têm um número reduzido desses profissionais ao seu alcance. Para solucionar esse problema, as comarcas deverão estimular e oferecer os cursos para formação de mediadores e conciliadores o mais rápido possível, a fim de tornar efetiva a proposta de resolução de lides de forma célere e eficaz.

Todavia, apesar das dificuldades explanadas, acredita-se que estas serão solucionadas progressivamente e não deverão desanimar os operadores do direito na busca por essa nova forma de solução de conflitos, que será benéfica para as partes e demais profissionais do meio forense Para melhor compreender 0 tema proposto, necessário se faz uma abordagem histórica acerca das relações de consumo, analisando ainda o desenvolvimento deste instituto com o decorrer do tempo e as características que sofreram ou não algum tipo de alteração.

Tratando da proteção ao consumidor, percebe-se que os primeiros resquícios foi o Código de Hamurabi, onde nesta codificação fazia previsão de um dispositivo capaz de regular a defesa dos que compravam algum bem ou contratava serviços.

No Antigo Egito existia uma concorrência entre os fabricantes de materiais utilizados para pintura corporal, e estes buscavam oferecer melhor qualidade para atender as diversas exigências dos que consumiam. Já na Idade Média, percebe-se a existência de preocupações referentes à qualidade dos produtos, como da apresentada nas espadas, por exemplo.

$\mathrm{Na}$ década de sessenta nos Estados Unidos que surgiu 0 consumerismo, considerado este como um movimento que tinha como objetivo principal assegurar a qualidade dos produtos e serviços, apresentando-se de maneira contrária aos que não atendessem os padrões de qualidade. 
O movimento citado foi um dos grandes responsáveis pela criação do direito do consumidor.

Em 1985, a Organização das Nações Unidas - ONU - decretou a Resolução $n^{\circ}$. 39/248, que reconhecia o princípio da vulnerabilidade do consumidor, haja vista diversas as experiências vivenciadas no intuito de proteger a figura do consumidor. Esta Resolução serviu para mostrar também à tentativa dos países de universalizar um dispositivo de proteção a figura do consumidor.

A ideia de consumo em terra pátria chegou por volta de 1930, junto com a grande industrialização ocorrida no país. A Lei n. 7.347/85 - Lei da Ação Civil Pública - observando a sua anterioridade a Constituição Federal e constituindo então como um marco na história do Direito do Consumidor, tendo em vista a sua visão defensiva da sociedade.

Ressalte-se que, ao mesmo tempo em que esta lei foi promulgada, foi criado no Brasil o Conselho Nacional de Defesa do Consumidor, reforçando a ideia de proteção ao consumidor e sua relação de consumo.

Em 1988, com o advento da Constituição Federal da República, o direito do consumidor ficou normativamente estabelecido no artigo 170, integrando o rol dos Princípios Gerais da Atividade Econômica. Vejamos (BRASIL, 1988):

Art. 170. A ordem econômica, fundada na valorização do trabalho humano e na livre iniciativa, tem por fim assegurar a todos existência digna, conforme os ditames da justiça social, observados os seguintes princípios:

I - soberania nacional;

II - propriedade privada;

III - função social da propriedade;

IV - livre concorrência;

$\mathrm{V}$ - defesa do consumidor

$\mathrm{VI}$ - defesa do meio ambiente, inclusive mediante tratamento diferenciado conforme o impacto ambiental dos produtos e serviços e de seus processos de elaboração e prestação; VII - redução das desigualdades regionais e sociais;

VIII - busca do pleno emprego;

IX - tratamento favorecido para as empresas de pequeno porte constituídas sob as leis brasileiras e que tenham sua sede e administração no país.

Parágrafo único: É assegurado a todos o livre exercício de qualquer atividade econômica, independentemente de autorização de órgãos públicos, salvo nos casos previstos em lei.

Após a inclusão da matéria referente ao consumidor na Constituição Federal e a busca por parte do legislador de organizar os dispositivos legais acerca do tema em uma única codificação, surge então o Código de Defesa do Consumidor. O CDC tem o intuito de regulamentar à relação de consumo em todo território nacional e também de estabelecer uma 
relação de equilíbrio nas relações de consumo.

\section{PRINCÍPIO DA VULNERABILIDADE}

O CDC, em seu art. $4^{\circ}$, inciso I, traz o principio da vulnerabilidade, sendo este considerado como de fundamental importância para a base de defesa do consumidor. Seu texto assegura que (BRASIL, 1990):

Art. $4^{\circ}$. A Politica Nacional das Relações de Consumo tem por objetivo o atendimento das necessidades dos consumidores, o respeito à sua dignidade, saúde e segurança, a proteção de seus interesses econômicos, a melhoria da sua qualidade de vida, bem como a transparência e harmonia das relações de consumo, atendidos os seguintes princípios:

I - reconhecimento da vulnerabilidade do consumidor no mercado de consumo;

Acerca deste principio, (NUNES 2000) nos traz uma abordagem precisa, esclarecendo que:

O consumidor é a parte fraca da relação jurídica de consumo. Essa fraqueza, essa fragilidade, é real, concreta e decorre de dois aspectos: um de ordem técnica e outro de cunho econômico. O primeiro está ligado aos meios de produção, cujo conhecimento é monopólio do fornecedor. E quando se fala em meios de produção não se está apenas referindo aos aspectos técnicos e administrativos para a fabricação de produtos e prestação de serviços que o fornecedor detém, mas também ao elemento que escolhe o que, quando e de que maneira produzir, de sorte que o consumidor está à mercê daquilo que é produzido.

A figura emblemática do consumidor no atual cenário é representada por aquele que adquire um produto ou prestação de serviço para si próprio ou para sua família. Essa representação vem ao encontro ao normatizado pelo CDC que estabelece que o consumidor seja a parte mais fragilizada na relação de consumo. Ou seja, o consumidor, diante de sua vulnerabilidade, é o que mais necessita de defesa.

Importante ressaltar acerca da vulnerabilidade, que esta pode ser verificada tanto no plano jurídico, como no técnico ou fático. Há ainda os que defendem a existência dela também no plano da informação. 
Quando se fala em vulnerabilidade técnica, entende-se que o comprador está em uma posição em que facilmente pode ser enganado no que diz respeito às características e qualidades do produto, haja vista este não ter conhecimento técnico sobre o que está sendo adquirido. Por sua vez, entende-se como vulnerabilidade jurídica a situação em que o consumidor não possui conhecimentos jurídicos necessários, onde se deduz a vulnerabilidade presumida no que diz respeito ao consumidor não profissional.

Para melhor abordar a vulnerabilidade fática, trazemos as palavras de (BENJAMIM, MARQUES e BESSA 2009, p. 75) onde explicam que:

[...] onde 0 ponto de concentração é outro parceiro contratual, o fornecedor que, por sua posição de monopólio, fático ou jurídico, por seu grande poder econômico ou em razão da essencialidade do serviço, impõe sua superioridade a todos que ele contratam, por exemplo, quando um médico adquire um automóvel através do sistema de consórcios para poder atender suas consultas e se submete às condições fixadas pela administradora de consórcios ou pelo próprio Estado.

Por fim, apresenta-se a vulnerabilidade informacional, onde entende-se que esta seja uma figura inerente ao próprio papel do consumidor, tendo em vista que a falta de conhecimento específicos sobre os bens e serviços é uma característica inerente ao consumidor.

A vulnerabilidade informacional é a "básica do consumidor, intrínseca e característica deste papel na sociedade". Isso porque "o que caracteriza o consumidor é justamente seu déficit informacional". O que fragiliza o consumidor não é a falta de informação, mas o fato de que ela é "abundante, manipulada, controlada e, quando fornecida, nos mais das vezes, desnecessária". Esta é a modalidade que mais justifica a proteção do consumidor, pois a informação inadequada sobre produtos e serviços é potencial geradora de incontáveis danos (BENJAMIM, MARQUES E BESSA; s.p, 2010).

Importante frisar novamente que é alvo de debates doutrinários as espécies de vulnerabilidade inerentes ao consumidor, onde alguns defendem as quatro modalidades - incluído a informacional - e outros que acreditam 
existir apenas as três primeiras mencionadas.

Saliente-se ainda, que 0 presente artigo tem a finalidade de abordar os contratos firmados por meio eletrônico, sendo este um meio muito utilizado atualmente, tendo em vista o seu poder de romper fronteiras e diminuir distâncias. $\mathrm{O}$ contrato eletrônico, via de regra, não conta com a presença física das partes contratantes quando é firmado. No entanto, celebram-se bastante essa modalidade pelo poder que possui de rapidez e interatividade na ação.

Contudo, mesmo nos contratos eletrônicos o consumidor apresenta-se como a parte vulnerável da relação. $E$, neste sentido, é que o Direito dá um salto à frente no que diz respeito às demais demandas judiciais que se referem ao direito do consumidor.

Entende-se, ainda, que quando se trata de contratos eletrônicos, é importante que 0 consumidor do ambiente virtual tenha suas normas regulamentadas. Uma iniciativa importante foi dada pela ONU Organização das Nações Unidas - que cuidou em criar a Comissão para o Comércio Internacional, podendo tais regras serem adotadas pelos países membros. Aqui no Brasil, já é possível observar algumas demandas judiciais que visam pedir uma postura estatal para intervenção nestes casos.

\section{APLICAÇÃO DO CÓdIGO DE DEFESA DO CONSUMIDOR AO COMÉRCIO ELETRÔNICO}

Verificamos a facilidade nas relações comerciais que 0 meio eletrônico proporcionou a sociedade de um modo geral. No entanto, esse crescente comércio também necessita de regulação judicial, tendo em vista que junto com as transações cresceram também as reclamações por parte dos consumidores. E a falta de legislação especifica acaba por dificultar a definição de jurisdição e aplicação das leis.

Percebe-se que a transação comercial efetuada por meio eletrônico utiliza-se de uma estrutura tecnológica, onde é feita a procura, oferta e o contrato por meio de transmissão de dados digitais. Desta forma, esta modalidade de transação comercial apresenta-se mais célere e mais cômoda para as partes. Contudo, 
surgiram também dificuldades no que se refere à aplicação dos dispositivos do Código de Defesa do Consumidor.

Importante ressaltar que " 0 contrato eletrônico caracteriza-se pelo meio empregado para celebrá-lo, cumpri-lo ou executá-lo, seja em uma ou nas três etapas de forma total ou parcial' (LORENZETTI, RICARDO. p. $551,2008)$. Desta forma, diversas são as consequências que poderão surgir com as formas de contrato, observando se este foi celebrado digitalmente ou por meio da web como forma de execução.

É sabido que a modalidade de contratos aqui tratada possui um alto

\subsection{PRINCÍPIO DA BOA-FÉ OBJETIVA}

O princípio da boa-fé objetiva é estabelecido como clausula geral no art. 4, inciso III e art. 51, inciso IV, do Código de Defesa do Consumidor (BRASIL, 1990). Se referindo a este princípio, imperioso se faz analisar as peculiaridades do comércio eletrônico, verificando sua compatibilidade com o principio em questão.

$\begin{array}{ccc}\text { Como já } & \text { apontado } \\ \text { anteriormente, } & \text { as } & \text { transações }\end{array}$

grau de insegurança jurídica, tendo em vista que o espaço virtual é de fácil acesso a toda a Sociedade nos dias de hoje, dificultando, desta forma, caracterizar a pretensão da transação. Sem contar ainda 0 fator da imaterialidade, dificultando perceber qual a real situação do bem ou dos sites que os ofertam.

Desta forma, podemos concluir que mesmo não havendo uma proteção de forma direito ao consumidor virtual, é possível vislumbrar que o Código de Defesa do Consumidor reserva sim proteção aos que efetuam transação comercial por meio eletrônico.

comerciais realizadas no ambiente eletrônico contam com suas próprias particularidades, fazendo com que estes os diferenciem do comércio tradicional, tendo como destaque a ausência da pessoa física, materialidade, territorialidade e atemporalidade nos contratos eletrônicos.

Contudo, acerca da discussão referente a aplicação do Código de 
Defesa do Consumidor ao comércio eletrônico, tendo em vista que este faz previsão as relações de consumo, independente da forma como foi realizada: se virtual ou a tradicional.

\subsection{DIREITO DE ARREPENDIMENTO}

As características das partes contratantes envolvidas nos contratos eletrônicos são importantes para que se definam a aplicabilidade ou não das regras do CDC. Importante verificar se as partes envolvidas no contrato serão caracterizadas como fornecedores e consumidores, caso sim, as normas deste código consumerista serão aplicadas.

Neste sentido que esclarece (LUCCA p. 109, 2003), dizendo que:

Aplicar-se-á total ou parcialmente - CDC às relações jurídicas, dependendo de serem ou não os sujeitos atuantes dessas relações fornecedores e consumidores. Identificados como tais, razão nenhuma existe para que a aplicação da legislação tutelar não Ihes seja aplicada.

No entanto, percebe-se que nem sempre é possível verificar com clareza e precisão como tais regras deverão ser aplicadas, haja vista a complexidade que se dá em torno da contratação realizada por meio eletrônico. Sem saber direito tais
Sendo assim, o princípio da boa-fé objetiva se torna de suma importância, tanto no comercio tradicional quanto no eletrônico.

regras, há muita divergência acerca da aplicação da cláusula que prevê o direito de arrependimento, que tem previsão no art. 48 do CDC.

As mesmas características que revestem as compras convencionais também estão presentes nas transações realizadas pela internet ou até mesmo por pedidos realizados por catálogos ou similares. Desta forma, é comum encontrar consumidores não satisfeitos com a aquisição de algum produto ou serviço, que não corresponde as suas expectativas. Nestes casos, o mais correto e justo seria a aplicação do direito de arrependimento para o comprador que fez a compra no ambiente virtual.

Em se tratando da localização do estabelecimento comercial, diversas são as interpretações dadas a este conceito, o que acaba por resultar em divergências doutrinárias e de interpretações. A corrente majoritária 
afirma que as transações comerciais realizadas eletronicamente podem ser equiparadas as realizadas em estabelecimentos convencionais.

Sendo assim, entende-se, portanto, que o consumidor terá até 07 (sete) dias a contar da assinatura do contrato ou recebimento do produto para que desista do contrato.

A maioria das jurisprudências pátrias tem seguido o entendimento da doutrina dominante no que diz respeito ao direito de arrependimento. Neste sentido podemos transcrever:

APELAÇÃO CÍVEL. COMPRA PELA INTERNET. LOJA VIRTUAL. ESPECIFICACÃO DO PRODUTO QUE NÃO O ADEQUADO AO CONSUMIDOR. DIREITO DE ARREPENDIMENTO. ART. 49 DO CDC. DEMORA INJUSTIFICADA DE RESSARCIMENTO DO VALOR PAGO. FALHA NA PRESTAÇÃO DO SERVICOO. RESPONSABILIDADE CIVIL. DANO MORAL. CARÁTER PUNITIVO E PEDAGÓGICO.

Nas compras realizadas fora do estabelecimento comercial da fornecedora de produtos, é conferido ao consumidor o direito de arrependimento, vez que o consumidor não tem a certeza de que está adquirindo um produto com as especificações e dimensões necessárias ao seu uso. A compra e venda utilizando a internet apresenta-se como uma realidade nos dias atuais, de modo a impor ao fornecedor a modernização e eficiência adequada para o cumprimento de sua obrigação. A situação privilegiada que estes se encontram, vez que apenas enviam os produtos comprados com o pagamento prévio do preço pelo consumidor, deve ser acompanhada de um dever de realizar a pronta restituição do valor pago quando da não concretização do negocio. A demora de meses para a devolução do valor despendido gera dano moral, que deve compreender um caráter punitivopedagógico.

Apesar do grande número de doutrinadores e julgados que acompanham tal entendimento, há aqueles que preferem usar de forma moderada, tal como Fábio Ulhoa de Coelho, que acredita que o disposto no art. 49 do CDC deve sim ser aplicado, porém com certa moderação. Segundo ele:

Não há direito de arrependimento se o consumidor puder ter, por meio da internet, rigorosamente as mesmas funções sobre o produto ou serviço que teria se 0 ato de consumo fosse praticado no ambiente físico e não no virtual (COELHO,. S.p, on line).

Contudo, na ocasião fica a não concordância ao pensamento do ilustre autor. Caso a compra ocorresse no ambiente físico, as informações de um determinado produto seriam questionáveis. Sem contar, ainda, que a solução por ele apresentada leva em consideração apenas as informações apresentadas, não considerando a cognoscibilidade delas.

Sendo assim, o entendimento apresentado pela doutrina de Fábio

Ulhoa Coelho não é considerável, Rev. Cereus, v. 9, n. esp, p.19-33, ago-dez./2017, UnirG, Gurupi, TO, Brasil. 
tendo em vista que havendo as informações suficientes, ao autor da compra ficou encarregada uma responsabilidade contrária. Entendese, portanto, que se o fornecedor entregar produto com apresentação diferente das informações mostradas na internet, dependendo do caso concreto, poderá o consumidor fazer valer o seu direito ao arrependimento,

\section{CONSIDERAÇÕES FINAIS}

Diante do exposto, fica a evidência de que a tarefa hermenêutica que norteia os contratos celebrados por meio eletrônico são distintos daquele que é usado na teoria geral dos contratos.

No entanto, há uma diferença entre as transações que celebram contratos eletrônicos e as que celebram os contratos convencionais, sendo características dos contratos virtuais a dificuldade técnica e de linguagem, o que pode acarretar insegurança $e$, consequentemente, erros na aquisição do produto, o que vem a impedir o estimulo para a realização de novos contratos.

$E$ aqui há uma necessidade de se firmar um entendimento pacifico na isto dentro dos limites impostos pelo principio da boa-fé objetiva.

De forma conclusiva, podemos entender que as regras do art. 49 do Código de Defesa do Consumidor poderão ser aplicadas aos contratos eletrônicos em duas hipóteses: a) após observância das características das ofertas que deu causa a contratação e b) na confiança do consumidor ao adquirir determinado produto

doutrina e jurisprudência acerca do tema. Contudo, percebe-se que estamos caminhando rumo a esse objetivo, sendo que o principal é a regulamentação uniforme das normas de comércio eletrônico. Só assim os consumidores gozarão de maior segurança jurídica ao celebrar tais transações comerciais.

Nos contratos comerciais celebrados no meio eletrônico, é necessário que o direito se preocupe em assegurar a proteção e estabelecer a confiança do consumidor com a outra parte do contrato. Deve, ainda, zelar pela qualidade dos produtos adquiridos, pondo em prática os princípios da boa-fé objetiva e da função social dos contratos. 
Desta forma, conclui-se que os contratos firmados na modalidade eletrônica podem a todo o momento serem reinventados, haja vista 0 constante avanço tecnológico percebido na sociedade. Sendo assim, devem também ser constantes os debates doutrinários

e posicionamentos jurisprudenciais acerca do tema.

\section{REFERÊNCIAS}

BENJAMIN, Antônio Herman V.; BESSA, Leonardo Roscoe; MARQUES, Cláudia Lima Marques. Manual de Direito do Consumidor. 2ª Ed. São Paulo: Saraiva, 2009.

BRASIL. Constituição da República Federativa do Brasil de 1988. Brasília: Senado Federal, 1988.

Lei $\mathrm{n}^{\circ}$. 8.078, de 11 de setembro de 1990. Dispõe sobre a proteção do consumidor e dá outras providencias. Brasília: Diário Oficial da República.

COELHO, Fábio Ulhoa. Direitos do consumidor no comércio eletrônico. Disponível em <http://www.ulhoacoelho.com.br/site/pt/artigos/doutrina/54-direitos-doconsumidor-no-comercio-eletronico.html>. Acesso em: 14 de mar. de 2016.

DE LUCCA, Newton. Aspectos Jurídicos da Contratação Informática e Telemática. São Paulo: Saraiva, 2003.

LORENZETTI, Ricardo Luís. A dogmática do contrato eletrônico. In: Direito \& Internet - Aspectos Jurídicos Relevantes (Vol III) - São Paulo: Quartier Latin do Brasil, 2008.

NUNES, Luiz Antonio Rizzatto. Curso de Direito do Consumidor. $4^{\circ}$ Ed. São Paulo: Saraiva, 2009. 